\title{
ВНУТРИКАЛЛУСНАЯ ИЗМЕНЧИВОСТЬ УДВОЕННЫХ ГАПЛОИДОВ РИСА, ПОЛУЧЕННЫХ В АНДРОГЕНЕЗЕ in vitro*
}

\author{
М.В. ИЛЮШКО 1 , М.В. РОМАШОВА' 1 , J.-M. ZHANG ${ }^{2}$, L.-W. DENG ${ }^{3}$, \\ D.-J. LIU 4 , R. ZHANG ${ }^{2}$, C.C. ГУЧEHKO1
}

Андрогенез in vitro - один из ведущих методов при создании исходного материала для селекции сельскохозяйственных культур. Многие селекционеры считают семенное потомство любого удвоенного гаплоида новой линией вне зависимости от того, с какого каллуса она получена. Однако в полевых условиях линии с одного каллуса часто выглядят одинаково и выбраковываются. Известно около 100 генов устойчивости к грибному возбудителю пирикуляриоза риса Pyricularia oryzae Cav. [Magnaporthe grisea (Hebert Barr.)]. В число наиболее актуальных генов для российского Дальнего Востока входят Pi-ta и $\mathrm{Pi}_{-1 a^{2}}$. В настоящей работе впервые выявлен внутрикаллусный морфологический полиморфизм и генетическая вариабельность удвоенных гаплоидов риса Oryza sativa L., полученных в андрогенезе in vitro гибридного растения, по генам устойчивости к пирикуляриозу Pi-ta и $\mathrm{Pi}-\mathrm{ta}^{2}$ вследствие гаметоклональной и сомаклональной изменчивости. Впервые среди удвоенных гаплоидов одной каллусной линии продемонстрирована мономорфность (отсутствие генетической вариабельности), обусловленная клональным размножением (митотическим делением) клеток каллуса. Целью нашей работы было изучение внутрикаллусной морфологической и генетической изменчивости удвоенных гаплоидов риса Oryza sativa L., полученных в андрогенезе in vitro гибридного растения. Опыты проводили в ФНЦ агробиотехнологий Дальнего Востока им. А.К. Чайки (Россия) и Институте селекции зерновых культур Хейлунцзянской академии сельскохозяйственных наук (Китай) в 2017-2018 годах. В качестве исходного растения для получения удвоенных гаплоидов риса использовали гибрид F1 сортов Дон $4237 \times$ Долинный. Сорт Долинный служит носителем аллелей генов $\mathrm{Pi}$-ta и $\mathrm{Pi}_{\text {- }} \mathrm{a}^{2}$, определяющих устойчивость к пирикуляриозу. В культуру in vitro было введено 386 гибридных пыльников. Каллусообразование составило 17,1\%. Сформировалось 18 каллусных линий с зелеными регенерантами, из которых для эксперимента отобрали шесть. По два семени каждой линии удвоенных гаплоидов высевали в почвогрунт в пластиковых стаканчиках и выращивали в условиях культуральной комнаты при $24{ }^{\circ} \mathrm{C}, 5000$ лк и режиме 16 ч (день)/8 ч (ночь). Через 90 сут после посева одно растение срезали и определяли окраску среза (наличие/отсутствие антоцианового пигмента). Отмечали следующие фазы роста и развития растений: поздняя стадия кущения, выход в трубку, выметывание, цветение. Удвоенные гаплоиды, находящиеся на первых двух указанных стадиях, были объединены в группу поздних. Ранними считали растения, достигшие фазы выметывания и цветения. После созревания отмечали дискретные признаки: наличие или отсутствие остей, их длину и окраску. ДНК выделяли из свежих листьев СТАВ-методом. Качество и количество ДНК определяли методом электрофореза в 1,0\% агарозном геле. Аллели генов $\mathrm{Pi}$-ta и $\mathrm{Pi}$ - $\mathrm{ta}^{2}$, определяющие устойчивость к пирикуляриозу, выявляли методом полимеразной цепной реакции. В качестве позитивного контроля для гена $P$ i-ta использовали растения китайского моногенного сорта K12, для гена Pi-ta $a^{2}$ сорта К27. Установлено, что удвоенные гаплоиды двух каллусных линий 7.2.2 и 21.2.1 были мономорфными, без генетической изменчивости по обоим генами устойчивости $\mathrm{Pi}$-ta и $\mathrm{Pi}$ - $\mathrm{ta}^{2}$. Семена растений каждой каллусной линии 7.2.2 и 21.2.1 в дальнейшем будут объединены в две отдельные селекционные линии, а большее число семян позволит интенсифицировать селекционный процесс. Среди удвоенных гаплоидов четырех других изученных каллусных линий (1.2.1, 4.1.2, 8.2.1 и 36.2.3) нами выявлен полиморфизм по остистости, скорости развития растений и антоциановой окраске среза. У каллусной линии 8.2.1 обнаружена генетическая изменчивость: 10 растений несли аллели устойчивости по обоим генам (Pi-ta и $P$ i-ta $\left.{ }^{2}\right), 8$ растений не имели ни одного аллеля, у 26 растений был детектирован только определяющий устойчивость аллель гена $\mathrm{Pi}-\mathrm{ta}^{2}$. Таким образом, при каллусообразовании в андрогенезе in vitro происходят два разнонаправленных процесса. Первый - это хорошо изученная сомаклональная изменчивость, которая ведет к полиморфизму клеток и регенерантов у растений. Второй представляет собой клонирование клеток, обусловливающее внутрикаллусное единообразие части регенерантов, а во многих случаях - всех регенерантов, полученных от одного пыльника. Мономорфные удвоенные гаплоиды после предварительной оценки по морфологическим и молекулярно-генетическим признакам составляют единый селекционный образец.

Ключевые слова: Oryza sativa, андрогенез in vitro, внутрикаллусная изменчивость, пири-

* Работа поддержана Программой совместной лаборатории Китая, стран СНГ и Центрально-Восточной Европы в рамках стратегии «Один пояс, один путь» (№ 2016АЕ6АЕ001). 
куляриоз, устойчивость, Pi-ta, Pi-ta ${ }^{2}$.

Андрогенез in vitro - один из ведущих методов при создании исходного материала для селекции многих сельскохозяйственных культур (1-3), включая рис Oryza sativa L. $(4,5)$. В подходящих условиях можно относительно легко получить значительное количество удвоенных гаплоидов, константных по морфологическим и генетическим признакам (расщепление отсутствует вследствие их гомозиготности), что позволяет сократить селекционный процесс на несколько лет $(1,4,6)$. При характеристике удвоенных гаплоидов исследователи, как правило, выявляют их изменчивость между сортами и гибридами $(5,7)$. Вопросы внутрисортовой/внутригибридной и внутрикаллусной изменчивости остаются малоизученными. По комплексу количественных признаков на сорте риса Каскад показаны достоверные различия между удвоенными гаплоидами двух каллусных линий, полученных из двух пыльников (9).

Теоретически считается, что один культивируемый in vitro пыльник может давать более 1000 гаплоидных растений (10), которые представляют собой клоны $(11,12)$. На одной каллусной линии риса формируются десятки (13), а иногда более сотни удвоенных гаплоидов. В этом случае все удвоенные гаплоиды одной каллусной линии можно было бы объединить в одну селекционную линию, что позволило бы ускорить селекционный процесс за счет увеличения массы семян одного образца. На примере пшеницы убедительно доказано происхождение андрогенных эмбриоидов из одной клетки (14). Известно, что существует геномная изменчивость регенерантов (гаплоиды-удвоенные гаплоиды-тетраплоиды) внутри одной каллусной линии риса, полученной от одного пыльника (13), поэтому вероятна и генетическая изменчивость среди удвоенных гаплоидов. Многие селекционеры априори считают семенное потомство любого удвоенного гаплоида новой линией $(8,15)$ вне зависимости от того, с какого каллуса она получена. Однако в полевых условиях линии с одного каллуса часто выглядят одинаково и выбраковываются, для дальнейшей работы остаются две или три. Обоснованность такого противоречивого подхода требует экспериментального подтверждения или опровержения полиморфизма и генетической изменчивости удвоенных гаплоидов одной каллусной линии.

Известно около 100 генов устойчивости к грибному возбудителю заболевания риса Pyricularia oryzae Cav. [Magnaporthe grisea (Hebert Barr.)] ceмейства $P i(16)$, большая часть из которых используется в селекции в разных регионах мира в зависимости от расоспецифичности патогена. В число наиболее актуальных генов для российского Дальнего Востока входят Pi-ta и $P i$ - $t a^{2}(17)$. Возможна их идентификация в растениях риса с помощью молекулярных маркеров (18-20).

В настоящей работе впервые выявлен внутрикаллусный морфологический полиморфизм и генетическая вариабельность удвоенных гаплоидов риса Oryza sativa L., полученных в андрогенезе in vitro гибридного растения, по генам Pi-ta и $P i-t a^{2}$ вследствие гаметоклональной и сомаклональной изменчивости. Впервые среди удвоенных гаплоидов одной каллусной линии продемонстрирована мономорфность в отсутствие генетической вариабельности, обусловленная клональным размножением (митотическим делением) клеток каллуса.

Нашей целью было изучение внутрикаллусной морфологической и генетической изменчивости удвоенных гаплоидов риса Oryza sativa L., полученных в андрогенезе in vitro гибридного растения.

Методика. Опыты проводили в ФНЦ агробиотехнологий Дальнего 
Востока им. А.К. Чайки (Россия) и Институте селекции зерновых культур Хейлунцзянской академии сельскохозяйственных наук (Китай) в 2017-2018 годах. В качестве исходного растения для получения удвоенных гаплоидов риса использовали гибрид $\mathrm{F}_{1}$ сортов Дон 4237 × Долинный, у которого при предварительной оценке регенерантов R1 была выявлена значительная внутрикаллусная изменчивость удвоенных гаплоидов по остистости. Сорт риса Долинный служит носителем аллелей генов Pi-ta и $\mathrm{Pi}_{\text {- }} \mathrm{a}^{2}$, определяющих устойчивость к перикуляриозу $(21,22)$. Методика создания удвоенных гаплоидов описана ранее (23). В каждой каллусной линии (всего 6 линий) брали семена (от 9 до 44 шт.) удвоенных гаплоидов первого поколения (всего 106 линий удвоенных гаплоидов), высевали по 2 шт. в почвогрунт в пластиковых стаканчиках и выращивали в условиях культуральной комнаты при $24{ }^{\circ} \mathrm{C}, 5000$ лк и режиме 16 ч (день)/8 ч (ночь). Из этих семян взошли регенеранты второго поколения $\mathrm{R}_{2}$, у которых изучали изменчивость морфологических признаков и фазы роста.

Через 90 сут после посева одно растение из каждой линии удвоенных гаплоидов R2 (всего 106 растений) срезали и определяли окраску среза (наличие/отсутствие антоцианового пигмента). C того же растения брали листья для выделения ДНК. На другом растении отмечали следующие фазы роста и развития: поздняя стадия кущения (наличие соломины без флагового листа, метелка не просматривается внутри соломины), выход в трубку (наличие соломины с флаговым листом, внутри которой просматривается метелка), выметывание (видны 5-6 верхних цветков метелки), цветение (метелка полностью видна). Удвоенные гаплоиды, находящиеся на первых двух указанных стадиях, были объединены в группу поздних. Ранними считали растения, находящиеся в фазах выметывания и цветения. После созревания отмечали дискретные признаки: наличие или отсутствие остей, их длину (короткие - менее 1 см или в виде шипиков на некоторых зерновках метелки, длинные - более 2 см) и окраску (белые, черные).

ДНК выделяли из свежих листьев СТАВ-методом (24). Качество и количество ДНК определяли методом электрофореза в 1,0 \% агарозном геле с использованием в качестве стандарта ДНК известной концентрации. Аллели генов Pi-ta и Pi-ta $a^{2}$ детерминирующие устойчивость, выявляли методом полимеразной цепной реакции (ПЦР). Для Pi-ta использовали пару праймеров 5' -AGCAGGTTATAAGCTAGGCC-3' и 5' -CTACCAACAAGTTCATCAAA-3' (18), для $P i-t a^{2}$ - пару 5'-CAGCGAACTCCTTCGCATACGCA-3' и 5'-CGAAAGGTGTATGCACTATAGTATCC-3' (20).

Реакцию проводили в 20 мкл реакционной смеси, содержащей $2 \times$ ПЦР буфер, 2,5 мM MgCl2, 0,2 мM dNTP, по 0,25 мкл прямого и обратного праймеров, 1 ед. Таq ДНК-полимеразы («Takara», Япония) и по 70-120 нг ДНК исследуемых образцов. Амплификацию осуществляли в 3-кратной повторности в термоциклере Veriti 96-Well Thermal Cycler («Applied Biosystems», США). Для гена Pi-ta использовали следующий температурный профиль реакции: 5 мин при $94{ }^{\circ} \mathrm{C}$ (начальная денатурация); 1 мин при $94{ }^{\circ} \mathrm{C}$ (денатурация), 1 мин при $56^{\circ} \mathrm{C}$ (отжиг праймеров), 1 мин при $72{ }^{\circ} \mathrm{C}$ (элонгация) (35 циклов); 10 мин при $72{ }^{\circ} \mathrm{C}$ (заключительная элонгация). Для гена $P i-t a^{2}$ режим был следующим: 5 мин при $95^{\circ} \mathrm{C}$ (начальная денатурация); 1 мин при $95{ }^{\circ} \mathrm{C}$ (денатурация), 1 мин при $60^{\circ} \mathrm{C}$ (отжиг праймеров), 1 мин при $72{ }^{\circ} \mathrm{C}$ (элонгация) (35 циклов); 10 мин при $72{ }^{\circ} \mathrm{C}$ (заключительная элонгация).

Продукты амплификации разделяли электрофоретически в 1,0\% агарозном геле на основе 0,5× ТВЕ буфера в камере Sub Cell Model 192 («Bio-Rad», США) с источником питания PowerPac Basic («Bio-Rad», США) 
и визуализировали в ультрафиолетовом свете с использованием системы гель-документирования Gel Doc XR+ («Bio-Rad», CША), предварительно окрашивая $1,0 \%$ раствором бромистого этидия. Наличие аллеля устойчивости признавали только в случае яркого окрашивания образцов ДНК.

В качестве позитивного контроля для гена $P i$-ta использовали растения китайского моногенного сорта К12, для гена $P$ i- $t a^{2}-$ сорта К27.

Результаты. В культуру in vitro было введено 386 гибридных пыльников. Каллусообразование составило 17,1 \% от их общего числа. Сформировалось 18 каллусных линий с зелеными регенерантами, что составило $27,3 \%$ от общего числа каллусов. Для эксперимента отобрали шесть каллусных линий с многочисленными удвоенными гаплоидами (табл. 1).

1. Регенерационная характеристика каллусных линий риса Oryza sativa L., полученных в андрогенезе in vitro у гибрида F1 сортов Дон $4237 \times$ Долинный

\begin{tabular}{l|c|c|c|c}
\hline \multirow{2}{*}{$\begin{array}{l}\text { Каллусная } \\
\text { линия }\end{array}$} & Число зеленых & \multicolumn{2}{|c|}{ Число удвоенных гаплоидов } & Объем выборки в экспе- \\
\cline { 3 - 4 } & регенерантов, шт. & шт. & $\%$ & 12 \\
1.2 .1 & 138 & 24 & 17 & 9 \\
4.1 .2 & 34 & 28 & 82 & 11 \\
7.2 .2 & 16 & 15 & 94 & 44 \\
8.2 .1 & 69 & 57 & 83 & 15 \\
21.2 .1 & 24 & 19 & 79 & 15 \\
36.2 .3 & 76 & 71 & 93 & \\
\hline
\end{tabular}

Результаты молекулярного маркирования показали, что отцовская форма (сорт Долинный) и исходный гибрид риса при электрофорезе продуктов амплификации имели характерную для аллеля устойчивости гена $P i$ ta зону в области 1042 п.н., а у материнской формы (сорт Дон 4237) этот ДНК-фрагмент отсутствовал (рис. 1).

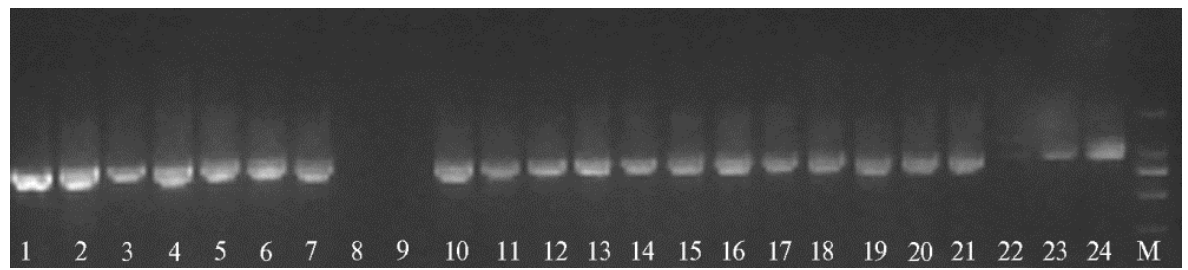

Рис. 1. Электрофоретическое разделение ПЦР-продуктов, полученных при выявлении гена устойчивости к пирикуляриозу Pi-ta у родительских растений, гибрида F1 сортов Дон $4237 \times$ Долинный и удвоенных гаплоидов $\mathbf{R} 2$ шести каллусных линий риса Oryza sativa L.: 1,2 - 1.2.1; 3, 4 - 4.1.2; 5,6 - 7.2.2; 7-16 - 8.2.1, 17, 18 - 21.2.1; 19, 20 - 36.2.3; 21 - сорт Долинный, 22 - сорт Дон 4237, 23 - гибрид F1 Дон $4237 \times$ Долинный, 24 - позитивный контроль, 1042 п.н. (моногенная линия K12), 25 - маркер молекулярной массы D2000 («TIANGEN», KHP).

Аллель гена $P i-t a^{2}$, определяющий устойчивость, был обнаружен у обеих родительских форм и гибрида. Удвоенные гаплоиды пяти каллусных линий $(1.2 .1,4.1 .2,7.2 .2,21.2 .1$ и 36.2.3) обладали аллелями устойчивости по обоим генам Pi-ta и $P i-t^{2}$ (табл. 2). Наблюдалась генетическая изменчивость среди удвоенных гаплоидов каллусной линии 8.2.1: 10 растений несли аллели устойчивости по обоим генам, у 8 растений оба аллеля отсутствовали, у остальных 26 растений выявили только аллель устойчивости $P$ i-ta ${ }^{2}$. Порядок дифференциации удвоенных гаплоидов на каллусной линии 8.2.1 слабо влиял на наличие детектируемых продуктов амплификации. Так, из 69 зеленых регенерантов, образовавшихся на каллусной линии 8.2.1 (см. табл. 1), удвоенные гаплоиды с аллелями устойчивости по обоим генам встречались среди порядковых номеров 1-44, с аллелями устойчивости только по гену $P$ i-ta ${ }^{2}$ - среди номеров 22-68. Аллели устойчивости обоих генов отсутствовали у части удвоенных гаплоидов с номерами от 2 до 69, то есть определенной очередности не наблюдалось. 
Анализ фенотипической изменчивости показал, что удвоенные гаплоиды каллусных линий 7.2.2 и 21.2.1 мономорфны. Полиморфизм наблюдался среди удвоенных гаплоидов четырех каллусных линий. Наибольшую морфологическую изменчивость отмечали у каллусной линии 8.2.1, и эта вариабельность не была связана с генетической изменчивостью удвоенных гаплоидов (см. табл. 2).

2. Генотипы и фенотипы удвоенных гаплоидов $\mathrm{R}_{2}$ каллусных линий риса Oryza sativa L., полученных у гибрида F1 сортов Дон 4237 × Долинный в андрогенезе in vitro

\begin{tabular}{|c|c|c|c|c|c|c|}
\hline \multirow{2}{*}{$\begin{array}{l}\text { Каллусная } \\
\text { линия }\end{array}$} & \multirow{2}{*}{$\begin{array}{l}\text { Удвоенные } \\
\text { гаплоиды, шт. }\end{array}$} & \multirow{2}{*}{$\begin{array}{l}\text { Окраска среза } \\
\text { стебля }\end{array}$} & \multirow{2}{*}{$\begin{array}{l}\text { Наличие и } \\
\text { длина остей }\end{array}$} & \multirow{2}{*}{$\begin{array}{l}\text { Тип } \\
\text { развития }\end{array}$} & \multicolumn{2}{|c|}{ Наличие генов } \\
\hline & & & & & $P i-t a$ & $P i-t a^{2}$ \\
\hline \multirow[t]{4}{*}{1.2 .1} & 2 & Антоциановая & Короткие & Ранний & + & + \\
\hline & 1 & Антоциановая & Отсутствуют & Ранний & + & + \\
\hline & 6 & Антоциановая & Короткие & Поздний & + & + \\
\hline & 3 & Антоциановая & Длинные & Поздний & + & + \\
\hline \multirow[t]{4}{*}{4.1 .2} & 2 & Антоциановая & Короткие & Ранний & + & + \\
\hline & 4 & Антоциановая & Короткие & Поздний & + & + \\
\hline & 1 & Антоциановая & Отсутствуют & Ранний & + & + \\
\hline & 2 & Антоциановая & Отсутствуют & Поздний & + & + \\
\hline 7.2 .2 & 11 & Без антоциана & Длинные & Поздний & + & + \\
\hline \multirow[t]{14}{*}{8.2 .1} & 3 & Антоциановая & Короткие & Ранний & + & + \\
\hline & 2 & Антоциановая & Длинные & Поздний & + & + \\
\hline & 1 & Без антоцитана & Длинные & Поздний & + & + \\
\hline & 3 & антоциановая & Отсутствуют & Ранний & + & + \\
\hline & 1 & Без антоциана & Отсутствуют & Ранний & + & + \\
\hline & 1 & антоциановая & Короткие & Ранний & - & + \\
\hline & 1 & антоциановая & Длинные & Ранний & - & + \\
\hline & 18 & антоциановая & Короткие & Поздний & - & + \\
\hline & 1 & антоциановая & Длинные & Поздний & - & + \\
\hline & 5 & Без антоциана & Короткие & Поздний & - & + \\
\hline & 1 & антоциановая & Короткие & Ранний & - & - \\
\hline & 5 & антоциановая & Короткие & Поздний & - & - \\
\hline & 1 & Без антоциана & Короткие & Ранний & - & - \\
\hline & 1 & Без антоциана & Короткие & Поздний & - & - \\
\hline 21.2 .1 & 15 & Антоциановая & Отсутствуют & Ранний & + & + \\
\hline \multirow[t]{2}{*}{36.2 .3} & 2 & Антоциановая & Отсутствуют & Ранний & + & + \\
\hline & 13 & Антоциановая & Отсутствуют & Поздний & + & + \\
\hline
\end{tabular}

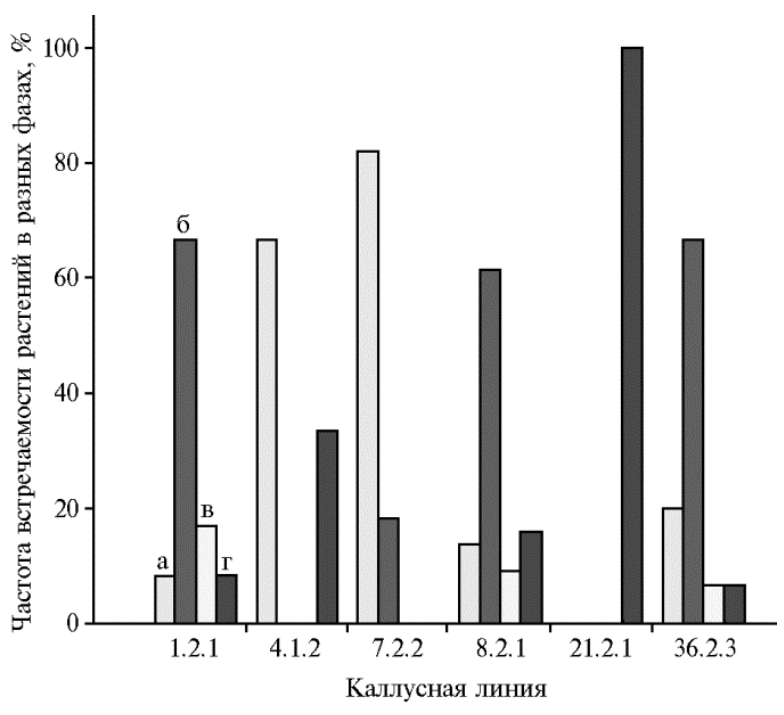

Рис. 2. Распределение удвоенных гаплоидов R2 риса Oryza sativa L. шести каллусных линий, полученных в андрогенезе in vitro гибрида F1 сортов Дон 4237 × Долинный, по фазам роста и развития через 90 сут после посева: а - кущение, б - выход в трубку, в - выметывание, г - цветение.
Детальное распределение удвоенных гаплоидов по фазам роста и развития представлено на рисунке 2. Все растения каллусной линии 21.2.1 цвели, изменчивость по другим признакам также не наблюдали. Растения линии 4.1.2 четко разделились на две группы: три ранних (в фазе цветения) и пять поздних (в фазе кущения), среди тех и других были остистые и безостые (см. табл. 2). Растения линии 7.2.2 по срокам прохождения как фазы кущения, так и фазы выхода в трубку были поздними и мономорфными по другим признакам. В трех из шести каллусных линий 
(1.2.1, 8.2.1 и 36.2.3) у удвоенных гаплоидов отмечали все четыре стадии роста и развития. ИЗ них линия 36.2.3 полностью безостая с антоциановой окраской среза соломины, то есть изменчивая только по скороспелости, линия 1.2.1 полиморфна по остистости и фазам роста и развития. В линии 8.2.1 удвоенные гаплоиды проявляли как генетическую, так и фенотипическую изменчивость, причем среди удвоенных гаплоидов было выявлено различное сочетание морфологических и генетических признаков (см. табл. 2). Изменчивость по окраске остей среди удвоенных гаплоидов одной каллусной линии мы не наблюдали: в линии 7.2.2 зерновки были с белыми остями, в линиях 1.2.1, 4.1.2 и 8.2.1 - с темными.

В пыльнике риса содержится около 1 тыс. пыльцевых зерен (25), которые могут быть индуцированы в каллус. Каллусная линия от одного пыльника формируется из каллусных агрегатов, которые могут быть образованы несколькими недозрелыми микроспорами. Это приводит как к полиморфизму и генетической изменчивости среди удвоенных гаплоидов, так и к геномной изменчивости регенератов одной каллусной линии (гаплоиды, удвоенные гаплоиды, тетраплоиды) (13). Однако не исключается и клональное размножение регенерантов в культуре in vitro. Так, для некоторых морфотипов и генотипов насчитывается от небольшого числа до нескольких десятков удвоенных гаплоидов, например 18 растений у каллусной линии 8.2.1 (см. табл. 2). Ранее мы выявили образование до 7-18 растений-тетраплоидов одной каллусной линии. Хотя полиморфизм тетраплоидов одной каллусной линии не изучался, столь массовое их формирование на одном каллусе скорее всего происходит за счет тиражирования $4 n$ каллусных клеток митозом (26). Удвоенные гаплоиды каллусных линий 7.2.2 и 21.2.1, которые мономорфны, можно рассматривать как идентичные растения и объединить при селекции в два отдельных образца. Аналогичный вариант использования очевиден и для групп одинаковых растений внутри других каллусных линий.

Особый интерес представляла каллусная линия 8.2.1, в которой встречались растения-регенеранты с аллелями одновременно двух генов устойчивости - Pi-ta и $P i$ - $t a^{2}$, только $P i$ - $t a^{2}$ и не несущих аллелей ни одного из этих генов. Существует несколько возможных объяснений подобного расщепления по генам $P i-t a$ и $P i-t a^{2}$ в линии 8.2.1. Один из родителей (сорт Долинный) был носителем аллеля гена $P i$-ta, определяющего устойчивость, и его гибрид унаследовал в гетерозиготе этот ген. Как следствие, часть удвоенных гаплоидов имели аллель гена устойчивости $P$ i-ta, а часть нет (см. рис. 1). Оба родителя и гибрид обладали аллелем гена устойчивости $P i-t a^{2}$, однако у 8 удвоенных гаплоидов (см. табл. 2) он отсутствовал. Праймеры, использованные в работе, были способны детектировать наличие или отсутствие аллеля гена, определяющего устойчивость, но не выявляли аллельного состояния гена. Можно предположить, что один из родителей (сорт Дон 4234) был гетерозиготен, а второй (сорт Долинный) гомозиготен по гену $\mathrm{Pi}-\mathrm{ta}^{2}$, тогда как гибрид оказался гетерозиготен по этому гену. Возможная схема дигибридного скрещивания, приведшая к генетической изменчивости среди удвоенных гаплоидов каллусной линии 8.2.1, представлена на рисунке 3. Получить три типа сочетания аллелей устойчивости в растениях-регенерантах возможно только во втором варианте скрещивания. Микроспоры типа $A B, a B$ и $a b$ индуцировали каллусообразование, далее произошло спонтанное удвоение хромосом и регенерация. Микроспоры четвертого типа $A b$ либо не образовали каллуса, либо 


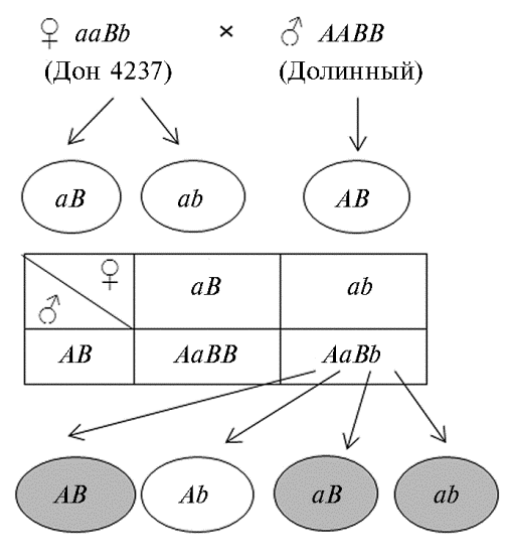

Рис. 3. Возможная схема дигибридного скрещивания родительских сортов риса Oryza sativa L. с получением каллуса из микроспор, приводящая к появлению удвоенных гаплоидов с двумя аллелями генов устойчивости к пирикуляриозу Pi-ta и $\mathrm{Pi}-\mathrm{ta}^{2}$, с одним аллелем (только по гену $P\left(-\mathrm{ta}^{2}\right)$ и без аллелей обоих генов устойчивости: А - аллель гена $P i-t a$, определяющий устойчивость, a - аллель гена $P i$ - $t a$, определяющий восприимчивость, В - аллель гена $P i-t a^{2}$, определяющий устойчивость, b - аллель гена $P i-t a^{2}$, определяющий восприимчивость.

Z. Wang с соавт. (27) считают гены $P i$-ta и $P i$ - $t a^{2}$ аллельными либо тесно сцепленными друг с другом. По данным Oryzabase (28), это один и тот же ген (7281 нуклеотид), выявляемый разными праймерами, амплифицирующими разные участки гена. Изучен полиморфизм аллелей гена $P$ i-ta у нескольких видов и сортов риса. Обнаружено, что только $99 \%$ аллелей схожи по нуклеотидной последовательности и имеют неоинаковую степень дивергенции (29). Правда, фенотипическое проявление, исследованное с помощью сортов-дифференциаторов, у генов Pi-ta и $\mathrm{Pi}-\mathrm{ta}^{2}$ значительно различается $(17,20,30)$. У изученных растений можно было ожидать либо наличие, либо полное отсутствие аллелей устойчивости для обоих генов. Однако у 26 растений присутствовал только определяющий устойчивость аллель ген $P i-t a^{2}$.

Явление сомаклональной изменчивости широко распространено в культуре клеток и тканей in vitro, обусловливает повышение генетической вариабельности и часто не затрагивает жизнеспособности регенерантов, полученных из каллуса (31-33). В нашем эксперименте не исключены генетические мутации, вызванные культивированием в условиях in vitro. Эти изменения могли произойти на участке ДНК гена Pi-ta, который не идентичен гену $P i-t a^{2}$, в каллусных клетках еще до спонтанного удвоения наборов хромосом с последующим образованием из них удвоенных гаплоидов. Нельзя исключить мутаций на участках ДНК, приведших к отсутствию устойчивых аллелей обоих генов у восьми растений удвоенных гаплоидов. В пользу этого говорит наличие устойчивых аллелей генов Pi-ta и $P i-t a^{2}$ среди удвоенных гаплоидов пяти других каллусных линий. Возможно, вследствие сомаклональной изменчивости, произошедшей уже после спонтанного удвоения, мы имеем в нескольких образцах риса любой из генов в гетерозиготном состоянии, что невозможно детектировать с помощью использованных праймеров.

Выявленный полиморфизм может свидетельствовать о том, что в пыльнике, который был использован при получении линии 8.2.1, индукция каллусообразования произошла минимум на 14 недозрелых микроспорах с последующим удвоением хромосом и регенерацией. Однако ранее отмечалась высокая частота изменений среди сомаклонов по физиологическим и количественным признакам, таким как время зацветания (выметывания метелки), сроки созревания, наличие или отсутствие остей, высота растений $(32,34)$. Посредством морфологического, биохимического и молекулярногенетического анализа выявлено, что в процессе сомаклональной изменчивости уже на ранних этапах культивирования происходят сходные генети- 
ческие преобразования, приводящие к появлению общих признаков в разных группах сомаклонов одного культурного вида (35). Такая совпадающая изменчивость может быть объяснена транспозиционными взрывами (34). Среди дигаплоидов табака и рапса встречаются выщепляющиеся морфологические мутанты, которые должны быть полностью гомозиготными (34). В случае сходной изменчивости у полученных нами удвоенных гаплоидов четырех каллусных линий $(1.2 .1,4.1 .2,8.2 .1,36.2 .3)$ возможны генетические изменения еще на стадии гаплоидных клеток с последующим спонтанным удвоением. Две другие каллусные линии, не затронутые этой изменчивостью, вероятно, более стабильны (7.2.2, 21.2.1). Следовательно, можно предположить, что на способность накопления мутационных изменений в культуре клеток in vitro значительное влияние оказывает не только сорт исходного растения, что установлено О.И. Кузнецовой с соавт. (33), но и генотип пыльцевого зерна, использованного для андрогенеза in vitro.

Андрогенез in vitro позволяет создавать огромное разнообразие линий удвоенных гаплоидов для селекционных программ. В частности, объединение мономорфных удвоенных гаплоидов одной каллусной линии в единую селекционную линию ускоряет селекционный процесс за счет увеличения количества семян одного образца. Также можно использовать наблюдаемое в некоторых каллусных линиях риса $O$. sativa разнообразие удвоенных гаплоидов, рассматривая каждый из них в качестве отдельной селекционной линии. Это особенно актуально для генотипов с затрудненным процессом андрогенеза in vitro: даже если каллусооразование удалось индуцировать только у одного из множества недозрелых пыльников, сформировавшаяся каллусная линия позволяет получить несколько полиморфных линий удвоенных гаплоидов.

На следующем этапе селекционной работы мы планируем изучить устойчивость полученных раннеспелых безостых линий удвоенных гаплоидов риса, несущих аллели обоих генов ( $P$ i-ta и $\left.P i-t a^{2}\right)$, при искусственном заражении штаммами $P$. oryzae, циркулирующими в Дальневосточной зоне рисосеяния.

Таким образом, нами впервые выявлен внутрикаллусный морфологический полиморфизм и генетическая вариабельность удвоенных гаплоидов риса Oryza sativa L., полученных в андрогенезе in vitro от гибридного растения, по генам устойчивости к пирикуляриозу $\mathrm{Pi}$-ta и $\mathrm{Pi}-\mathrm{ta}^{2}$. В результате выполненных исследований выделены удвоенные гаплоиды каллусных линий 7.2.2 и 21.2.1, которые мономорфны и не проявляют генетической изменчивости по обоим генами устойчивости ( $P$ i-ta и $\left.P i-t a^{2}\right)$. Среди удвоенных гаплоидов четырех других изученных каллусных линий $(1.2 .1,4.1 .2$, 8.2.1 и 36.2.3) обнаружен полиморфизм по остистости, скорости развития растений и антоциановой окраске среза. У каллусной линии 8.2.1 показана генетическая изменчивость, что проявляется в наличии у растений аллелей обоих генов $P i$-ta и $P i-t a^{2}$, только одного гена $P i-t a^{2}$ или отсутствие аллелей обоих генов. При каллусообразовании в андрогенезе in vitro происходят два разнонаправленных процесса. Первый и хорошо изученный - это сомаклональная изменчивость, ведущая к полиморфизму клеток и растений-регенерантов. Второй - клонирование клеток с возникающим вследствие этого внутрикаллусным единообразием, единообразием части регенерантов, а во многих случаях всех регенерантов, полученных от одного пыльника. Мономорфные удвоенные гаплоиды после предварительной оценки по морфологическим и молекулярно-генетическим признакам составляют единый 
1ФГБНУ ФНЦ агробиотехнологий Дальнего Востока

692539 Россия, Приморский край, г. Уссурийск, пос. Тимирязевский,

ул. Воложенина, 30 ,

e-mail: ilyushkoiris@mail.ru $\bowtie$, romashova_1969@mail.ru,

lana_svet8@mail.ru;

${ }^{2}$ Chinese-Russian Center for Science and Technology

in Agricultural Cooperation

Heilongjiang Academy of Agricultural Sciences,

150086 China, 368 Xuefu Rd, Nangang District, Harbin, Heilongjiang,

e-mail: zjm312@aliyun.com,zr0705@126.com;

${ }^{3}$ Biotechnology Research Institute,

Heilongjiang Academy of Agricultural Sciences,

150086 China, 368 Xuefu Rd, Nangang District, Harbin, Heilongjiang,

e-mail: lucydlw@163.com;

${ }^{4}$ Crop Resources Institute,

Heilongjiang Academy of Agricultural Sciences,

150086 China, 368 Xuefu Rd, Nangang District, Harbin, Heilongjiang,

e-mail: dongdong415@126.com

Sel'skokhozyaistvennaya biologiya [Agricultural Biology], 2020, V. 55, № 3, pp. 533-543

\title{
INTRA-CALLUS VARIABILITY OF RICE DOUBLED HAPLOIDS GENERATED THROUGH in vitro ANDROGENESIS
}

\author{
M.V. Ilyushko', M.V. Romashova1, J.-M. Zhang2, L.-W. Deng'3, D.-J. Liü ${ }^{4}$, R. Zhang', \\ S.S. Guchenko ${ }^{1}$
}

${ }^{1}$ Chaika Federal Research Center of Agricultural Biotechnology of the Far East, 30, ul. Volozhenina, pos. Timityazevskii, Ussuryisk, Primorskii Krai, 692539 Russia, e-mail ilyushkoiris@mail.ru ( $\square$ corresponding author), romashova_1969@mail.ru, lana_svet8@mail.ru;

${ }^{2}$ Chinese-Russian Center for Science and Technology in Agricultural Cooperation, Heilongiiang Academy of Agricultural Sciences, 368 Xuefu Rd, Nangang, Harbin, Heilongjiang, China 150086, e-mail zjm312@aliyun.com, zr0705@126.com; ${ }^{3}$ Biotechnology Research Institute, Heilongjiang Academy of Agricultural Sciences, 368 Xuefu Rd, Nangang, Harbin, Heilongjiang, China 150086, e-mail lucydlw@163.com;

${ }^{4}$ Crop Resources Institute, Heilongjiang Academy of Agricultural Sciences, 368 Xuefu Rd, Nangang, Harbin, Heilongjiang, China 150086, e-mail dongdong415@126.com

ORCID:

Ilyushko M.V. orcid.org/0000-0001-7042-8641 Romashova M.V. orcid.org/0000-0002-7426-8523

Zhang J.-M. orcid.org/0000-0003-0662-5098 Deng L.-W. orcid.org/0000-0002-4325-0080

Lui D.-J. orcid.org/0000-0002-1002-5266

Guchenko S.S. orcid.org/0000-0003-3492-8934

Zhang R. orcid.org/0000-0002-2338-7469

The authors declare no conflict of interests

Acknowledgements:

Supported financially by the Joint Laboratory Program of China, the CIS and Central-Eastern Europe countries as part of the One Belt - One Way Strategy (No. 2016AE6AE001)

Received June 7, 2019

doi: 10.15389/agrobiology.2020.3.533eng

\section{Abstract}

In vitro androgenesis is among the leading methods in creating source material for crop breeding. Many breeders a priori consider the seed progeny of any doubled haploid a new line, regardless of which callus the line was obtained from. In practice, it often turns out that in field conditions the lines from one callus are outwardly identical, so the breeders discard them, leaving two or three of ones for further work. The validity of such a controversial approach requires experimental confirmation or refutation of polymorphism and genetic variability of doubled haploids of the same callus line. About 100 genes of rice resistance to Pyricularia oryzae Cav. [Magnaporthe grisea (Hebert Barr.)] are known of which Pi-ta и $P i$ - $t a^{2}$ are the most relevant for the Russian Far East. This paper is the first to report intracallus morphological polymorphism and genetic variability for $P i$-ta и $P i-t a^{2}$ genes due to gametoclonal and somaclonal variability of rice Oryza sativa L. doubled haploids derived from a hybrid plant via in vitro androgenesis. For the first time, a monomorphism in the absence of genetic variability due to callus cell clonal reproduction (mitotic division) was revealed among doubled haploids produced by the same callus line. Our work aimed to study the intracallus morphological and genetic variability of Oryza sativa L. doubled rice haploids derived in vitro androgenetically from a hybrid plant. Experiments were performed in 2017-2018 at the Federal Research Center of Agricultural Biotechnology of the Far East (Russia) and the Crop Resources Institute, Heilongjiang Academy of Agricultural 
Sciences, (China). A F1 Don $4237 \times$ Dolynniy rice hybrid was used. A total of 386 anthers of this hybrid were cultured in vitro with the callus formation rate of $17.1 \%$. Six of eighteen callus lines producing green regenerants were selected for further study. Two seeds of each doubled haploid line were sown in soil and grown in plastic pots (a culture room, $24{ }^{\circ} \mathrm{C}, 5000$ lux, 16 hours/8 hours day/night). One plant of each pair was cut 90 days after sowing to assess the presence/absence of anthocyanin coloration. Plant growth stages (late tillering, stem extension, heading, and flowering) were recorded. Doubled haploids that reached the first two of these stages were assigned to a later group, and those that reached the heading and flowering stages were combined into an early group. The presence or absence of awns, their length and color were estimated after maturation. DNA was extracted from fresh leaves by CTAB method. The DNA quality and quantity were estimated electrophoretically using a $1.0 \%$ agarose gel. Alleles of the $P i-t a$ and $P i-t a^{2}$ genes which determine blast resistance were detected by PCR method. Plants of the Chinese monogenic variety K12 were a positive control for Pi-ta gene, and varieties K27 for $P i$ - $t a^{2}$ gene. The doubled haploids of two callus lines, 7.2.2 and 21.2.1, are monomorphic without genetic variability for both resistance genes, Pi-ta and Pi$t a^{2}$. Plant seeds of each callus line (7.2.2 and 21.2.1) will be further combined into two separate breeding lines to intensify breeding due to a larger number of seeds. Doubled haploids of the callus lines 1.2.1, 4.1.2, 8.2.1, 36.2.3 are polymorphic in awn formation, plant growth stage and anthocyanin pigmentation of stem cuts. The callus line 8.2.1 is genetically variable (ten plants carried alleles of both resistance genes, $P i$-ta and $P i$ - $t a^{2}$, eight plants possessed none of the alleles, and in 26 plants only $P i$ $t a^{2}$ allele was detected). Thus, upon callus formation via in vitro androgenesis, the two opposite processes occurred are somaclonal variation and cell cloning. Somaclonal variation leads to polymorphism of callus cells and plant-regenerants, while cell cloning determines intra-callus uniformity, as well as the uniformity of some regenerants (and, in many cases, all regenerants derived from the same anther). Monomorphic doubled haploids, after a preliminary assessment for morphological traits and molecular characteristics, comprises a single selection sample.

Keywords: Oryza sativa, in vitro androgenesis, intra-callus variability, rice blast, resistance, $P i-t a, P i-t a^{2}$.

\section{REFEREN CES}

1. Germana M.A. Anther culture for haploid and doubled haploid production. Plant Cell Tiss. Organ. Cult., 2011, 104(3): 283-300 (doi: 10.1007/s11240-010-9852-z).

2. Ferrie A.M.R., Caswell K.L. Isolated microspore culture techniques and recent progress for haploid and doubled haploid plant production. Plant Cell Tiss. Organ. Cult., 2011, 104(3): 301-309 (doi: 10.1007/s11240-010-9800-y).

3. Dunwell J.M. Haploids in flowering plants: origins and exploitation. Plant Biotechnology Journal, 2010, 8(4): 377-424 (doi: 10.1111/j.1467-7652.2009.00498.x).

4. Mishra R., Rao G.J.N. In-vitro androgenesis in rice: advantages, constraints and future prospects. Rice Science, 2016, 23(2): 57-68 (doi: 10.1016/j.rsci.2016.02.001).

5. Sarao N.K., Gosal S.S. In vitro androgenesis for accelerated breeding in rice. In: Biotechnologies of crop improvement. Vol. 1. S.S. Gosal, S.H. Wani (eds.). Springer, Cham, 2018: 407-435 (doi: 10.1007/978-3-319-78283-6_12).

6. Datta S.K. Androgenic haploids: factors controlling development and its application in crop improvement. Current Sci., 2005, 89(11): 1870-1878.

7. Mishra R., Rao G.J.N., Rao R.N., Kaushal P. Development and characterization of elite doubled haploid lines from two indica rice hybrids. Rice Science, 2015, 22(6): 290-299 (doi: 10.1016/j.rsci.2015.07.002).

8. Lapitan V.C., Redoña E.D., Abe T., Brar D. Molecular characterization and agronomic performance of DH lines from the F1 of indica and japonica cultivars of rice (Oryza sativa L.). Field Crops Research, 2009, 112(2-3): 222-228 (doi: 10.1016/j.fcr.2009.03.008).

9. Ilyushko M.V., Romashova M.V. Variability of rice haploids obtained from in vitro anther culture. Russian Agricultural Sciences, 2019, 45(3): 243-246 (doi: 10.3103/S1068367419030108).

10. Sibikeeva Yu.E., Sibikeev S.N. Genetika, 2014, 50(7): 831-839 (doi: 10.7868/S0016675814070169) (in Russ.).

11. Kruglova N.N. Agrarnaya Rossiya, 2009, 1: 34-38 (in Russ.).

12. Heberle-Bors E. In vitro haploid formation from pollen: a critical review. Theoret. Appl. Genetics, 1985, 71: 361-374 (doi: 10.1007/BF00251175).

13. Ilyushko M.V., Romashova M.V. Argarnyi vestnik Primor'ya, 2018, 1(9): 5-8 (in Russ.).

14. Sel'dimirova O.A., Kruglova N.N. Uspekhi sovremennoi biologii, 2014, 134(5): 476-487 (in Russ.).

15. Mishra R., Rao G.J.N., Rao R.N., Kaushal P. Development and characterization of elite doubled haploid lines from two indica rice hybrids. Rice Science, 2015, 22(6): 290-299 (doi: 10.1016/j.rsci.2015.07.002).

16. Wu Y., Xiao N., Chen Y., Yu L., Pan C., Li Y., Zhang X., Huang N., Ji H., Dai Z., Chen X., 
Li A. Comprehensive evaluation of resistance effects of pyramiding lines with different broadspectrum resistance genes against Magnaporthe oryzae in rice (Oryza sativa L.). Rice, 2019, 12: 11 (doi: 10.1186/s12284-019-0264-3).

17. Sankin A.Yu., Lelyavskaya V.N., Sun I.T. Uspekhi sovremennoi nauki, 2017, 2(10): S. 26-28 (in Russ.).

18. Dai X.-J., Yan Y.-Z., Zhou L., Liang M.-Z., Fu X.-C., Chen L.-B. Distribution research of blast resistance genes Pita, Pib, Pi9 and Pikm in blast-resistant rice resources. Life Sci. Research, 2012, 16(4): 340-356 (doi: 10.16605/j.cnki.1007-7847.2012.04.009).

19. Orasen G., Greco R., Puja E., Pozzi C., Stile M.R. Blast resistance $R$ genes pyramiding in temperate japonica rice. Euphytica, 2020, 216: 40 (doi: 10.1007/s10681-020-2575-2).

20. Wang J.C., Correll J.C., Jia Y. Characterization of rice blast resistance genes in rice germplasm with monogenic lines and pathogenicity assays. Crop Protection, 2015, 72: 132-138 (doi: 10.1016/j.cropro.2015.03.014).

21. Ilyushko M.V., Fisenko P.V., Sunitskaya T.V., Guchenko S.S., CHzhan TS., Den L.-V., Kostylev P.I. Zernovoe khozyaistvo Rossii, 2017, 4: 41-45 (in Russ.).

22. Ilyushko M.V., Romashova M.V., Fisenko P.V., Sunitskaya T.V., Guchenko S.S., Lelyavskaya V.N. Vestnik zashchity rastenii, 2019, 1(99): 36-39 (doi: 10.31993/2308-6459-20191(99)-36-39) (in Russ.).

23. Ilyushko M.V., Romashova M.V. Dal'nevostochnyi agrarnyi vestnik, 2017, 4(44): 37-45 (in Russ.).

24. Gennaya inzheneriya rastenii. Laboratornoe rukovodstvo /Pod redaktsiei Dzh. Dreipera, R. Skotta, F. Armitidzha, R. Uoldena [Genetic engineering of plants. Laboratory manual]. Moscow, 1991 (in Russ.).

25. Farrell T.C., Fox K.M., Williams R.L., Fukai S. Genotypic variation for cold tolerance during reproductive development in rice: screening with cold air and cold water. Field Crops Research, 2006, 98(2-3): 178-194 (doi: 10.1016/j.fcr.2006.01.003).

26. Ilyushko M.V., Romashova M.V. Rossiiskaya sel'skokhozyaistvennaya nauka, 2020, 3: 14-17 (doi: 10.31857/S2500262720030047) (in Russ.).

27. Wang Z., Jia Y., Fjellstrom R.G. The relationship between the rice blast resistance genes $P i$-ta and Pi-ta ${ }^{2}$. Journal of Zhejiang wanly university, 2004, 17(2): 91-92.

28. Integrated Rice Science Database. Available: http://shigen.nig.ac.jp/rice/oryzabase/gene/detail/947. Accessed: 30.08 .2018 .

29. Ramkumar G., Madhav M.S., Rama Devi S.J.S., Manimaran P., Mohan K.M., Prasad M.S., Balachandran S.M., Neeraja C.N., Sundaram R.M., Viraktamath B.C. Nucleotide diversity of Pita, a major blast redistance gene and identification of its minimal promoter. Gene, 2014, 546(2): 250-256 (doi: 10.1016/j.gene.2014.06.001).

30. Ma J.-T., Zhang G.-M., Xin A.-H., Zhang L.-Y., Deng L.-W., Wang Y.-L., Wang Y., Ran Y., Gong X.-J., Ge X.-L., Yang X.-F. Comparison of pathogenicity of Pyricularia oryzae under different genetic backgrounds. Acta Agronomica Sinica, 2015, 41(12): 1791-1801 (doi: 10.3724/SP.J.1006.2015.01791).

31. Yamamoto T., Soeda Y., Nishikawa A., Hirohara H. A study of somaclonal variation for rice improvement induced by three kinds of anther-derived cell culture techniques. Plant Tissue Culture Letters, 1994, 11(2): 116-121 (doi: 10.5511/plantbiotechnology 1984.11.116).

32. Ezhova T.A., Bagrova A.M., Khartina G.A., Gostimskii S.A. Genetika, 1989, XXV(5): 878-885 (in Russ.).

33. Kuznetsova O.I., Ash O.A., Gostimskij S.A. The effect of duration of callus culture on the accumulation of genetic alteration in pea Pisum sativum L. Russian Journal of Genetics, 2006, 42(5): 555-562 (doi: 10.1134/s1022795406050139).

34. Scowcroff W.R. Somaclonal variation: the myth of clonal uniformit. In: Genetic flux in plant. B. Hohn, E.S. Dennis (eds.). Wien, New York: Springer-Verlas, 1985: 217-245 (doi: 10.1007/9783-7091-8765-4).

35. Osipova E.S., Koveza O.V., Gostimskij S.A., Troitskij A.V., Dolgikh Yu.L., Shamina Z.B. Analysis of specific RAPD and ISSR fragments in maize (Zea mays L.) somaclones and development of SCAR markers on their basis. Russian Journal of Genetics, 2003, 39(12): 1412-1419 (doi: 10.1023/B:RUGE.0000009156.74246.bc). 